\title{
Extraction of Borassus flabilifer root and biochemical effects on experimental mouse model- lipid profile
}

\author{
Rajib Dab Nath', Md. Sohel Rana ${ }^{2}$, Md. Areeful Haque ${ }^{3}$, Pobittro Sen ${ }^{4}$, Md. Elias Mehedy ${ }^{5}$, \\ Mrityunjoy Biswas ${ }^{6, *}$ \\ ${ }^{1}$ Department of Pharmacy, Noakhali Science \& Technology University, Noakhali, Bangladesh \\ ${ }^{2}$ Department of Pharmacy, Jahangirnagar University, Dhaka, Bangladesh \\ ${ }^{3}$ Department of Pharmacy, International Islamic University Chittagong, Chittagong, Bangladesh \\ ${ }^{4}$ Department of Pharmacy, Stamford University, Dhaka, Bangladesh \\ ${ }^{5}$ Department of Microbiology, University of Chittagong, Chittagong, Bangladesh \\ ${ }^{6}$ Department of Biochemistry and Molecular Biology, University of Rajshahi, Rajshahi, Bangladesh
}

\section{Email address:}

rajibpharma08@mail.com (R. D. Nath), sohelrana.ju@juniv.edu (S. Rana), areeful@gmail.com (A. Haque), pobitrosen@gmail.com (P. Sen), emh786@gmailcom (E. Mehedy),mrityunbio@gmail.com (M. Biswas)

\section{To cite this article:}

Rajib Dab Nath, Md. Sohel Rana, Md. Areeful Haque, Pobittro Sen, Md. Elias Mehedy, Mrityunjoy Biswas. Extraction of Borassus Flabilifer Root and Biochemical Effects on Experimental Mouse Model- Lipid Profile. American Journal of Life Sciences. Vol. 3, No. 1, 2015, pp. 6-10. doi: $10.11648 /$ j.ajls.20150301.12

\begin{abstract}
In this investigation we included an extraction of Borassusflabilifer root and reported to have beneficial effect in lowering of blood pressure and treatment of hypertensive patients. Borassusflabilifer root were collected from various part of Noakhali and extract was prepared by following standard method. The present study was conducted to determine the in vivo effect of Borassusflabilifer root extract on tissues and serum lipids in experimental rats. 15 male Wistar rats were randomly divided into 3 groups and administered different doses of the extract for 30 days while control group received distilled water. Lipid profile in the serum, liver, kidney and heart of the experimental animals were measured and compared with the control. Borassusflabilifer caused significant $(\mathrm{p}<0.0)$ reduction in serum total cholesterol and LDL cholesterol in a dose dependent manner in rats while serum HDL cholesterol was significantly elevated. Serum triglyceride level was not significantly affected. There was also a significant increase in the levels of total cholesterol and triglyceride in the liver while lipid profile in the heart and Kidney were unaffected. This result suggests positive alterations in lipid metabolism and storage in rats which corroborate the efficacy of Borassusflabilifer root extract in the management of atherosclerosis caused by lipid abnormalities. We can develop techniques on rational design of drug for the treatment of heart diseases and further study can lead to the development of a therapy for other diseases like diabetes.
\end{abstract}

Keywords: Hypertension, HDL, LDL, Triglyceride, Atherosclerosis, Rational Design

\section{Introduction}

Medicinal plants constitute an important component of flora and are widely distributed in Bangladesh. The pharmacological evaluation of substances from plants is an established method for the identification of lead compounds which can leads to the development of novel and safe medicinal agents. Bangladesh, our motherland, has been naturally rewarded with a suitable tropical climate and fertile soil, Bangladesh possesses a rich flora of tropical plants. Around 5000 species of phanerogams and pteridophytes grow in its forests, jungles, wastelands and roadsides as indigenous, naturalised and cultivated plants. Out of them, more than a thousand have been claimed to possess medicinal and / or poisonous properties, of which 546 have recently been enumerated with their medicinal properties and therapeutic uses [1]. Its plant sources have great use as medicine as well as nutritive value. Borassus flabellifer of them is a plant which is belongs to the family Arecaceae. Today palm is mainly cultivated in the drier parts of its geographical range. It is usually grown in strictly seasonal tropical or subtropical climates on sandy soils. The Palmae plant, Borassus flabillifer 
L. is widely distributed and cultivated in tropical Asian countries such as Thailand, Bangladesh, India, Myanmar, Sri Lanka, Malaysia, etc.[2]. In Bangladesh, it occurs over the country, particularly in the Barind areas.

Oxidative damage plays a significantly pathological role in human disease. Cancer, emphysema, cirrhosis, arteriosclerosis, and arthritis have all been correlated with oxidative damage[3] Also, excessive generation of ROS, which is induced by various stimuli, when exceeds the antioxidant capacity of the organism, leads to a variety of pathophysiological processes such as inflammation, diabetes, genotoxicity and cancer. Overwhelming evidence has accumulated showing that natural products from plants, microorganisms and marine organisms comprise major portion of the total repertoire of the available anticancer drugs [4. Research interest on screening of medicinal plants has intensified in recent years with a view to finding out potential cytotoxic principle for cancer chemotherapy [5]. The antimicrobial properties of the medicinal plants are reported from all over the world recently [6] and used in the treatment of many diseases such as AIDS and sexually transmitted diseases [7]. Whereas there are some advantages of using antimicrobial compounds of medicinal plants, such as often fewer side effects, better patient tolerance relatively less expensive, acceptance due to long history of use and being renewable in nature. Examples of drugs derived from secondary plant metabolites and their derivatives, or conceived from pharmacological knowledge gained from studies of herbal remedies, are abundant. In a systematic analysis published in 1997, it was assessed that 157 of 520 drugs (30\%) approved by Food and Drug Administration (FDA) in the USA during 1983-94were natural products or their derivatives [8].

Everything keeping in mind the present study was designed to identify the toxicological activities of the extracts of the plant. The crude extracts of Borassus flabilifer L. Roots are orally administered to Rats for one month then its toxicological effects are investigated by measuring different biochemical parameter of the blood serum. The Serum cholesterol, Triglyceride (TG), High density lipoprotein (HDL) of blood serum are measured to identify the effect of the extraction of Borassus flabilifer L. Roots on lipid profile. Serum creatinine level is measured to identify the toxicological effect of the drugs on kidney function. Serum glutamate pyruvic acetate (SGPT) enzyme level is measured to identify the toxicological effect of the extracts on liver function.

\section{Materials \& Methods}

\subsection{Preparation of Crude Extracts}

Collection \& identification: At first with the help of a comprehensive literature review borassus fhabilifer from arecaceae family was selected for this investigation. The roots of the plants were collected from dhamrai, Dhaka, Bangladesh \& identified taxonomist of the national herbarium of Bangladesh, mirpur Dhaka. The voucher specimens of the plants have been deposited in the herbarium for further reference.

Extraction procedure: After collection of root it was dried on sun make it powdered form and $100 \mathrm{mg}$ of powder used for extraction by Soxhlet apparatus at elevated temperature (60 C) using $100 \%$ menthol. Here $500 \mathrm{ml}$ of each solvent are used. After each extraction the plant materials are dried and used again for next extraction. Extraction are considered to be complete when the plant materials become exhausted of their constituents that are confirmed from cycles of colorless liquid siphoning in the Soxhlet apparatus. After Methanol extracts was completed the materials were dried and soaked into distilled. The plant materials are kept in water for 7 days in scaled container accompanying occasional shaking \& stirring. All two extracts were filtered individually through fresh cotton bed. The filters obtained were dried at temperature of $40+2 \mathrm{C}$ to have gummy concentrate of the crude extracts. Each extracts was kept in suitable container with proper labeling and stored in cold and dry place.

\subsection{Experimental Animal and Experimental Design}

Table 1. Group distribution and administered substance with their dose.

\begin{tabular}{ll}
\hline Group Number & Administered Substances and Dose \\
\hline Group 1 & Control(purified water) \\
Group 2 & BFM-100(300 $\mathrm{mg} / \mathrm{kg} \mathrm{bw})$ \\
Group 3 & BFM-100(600 $\mathrm{mg} / \mathrm{kg} \mathrm{bw})$ \\
\hline
\end{tabular}

Here BFM-100=100\% Methanol extract of B. Flabilifer, BW= body weight. All doses are administered orally.

Fifteen healthy male albino rats (Rattus novergicus) average weight $150 \mathrm{~g}$ were obtained from the departmental Animal House of pharmacy department at Jahangirnagar University, Savar. The animals were housed in Plastic cages and had free access to rat pellets and water.

Animals are divided into three groups of five animals each

\subsection{Preparation of Serum}

After applying General anesthesia (Ketamin) on the rats, they are sacrificed by cervical dislocation. Blood samples were collected by syringe into small centrifugal test tube. Serum was prepared by aspiration of the clear yellowish liquid after clotting and centrifuged for 10 minutes at 3000rpm in an MSC (Essex, UK) bench centrifuge.

\subsection{Determination of Lipid Profile}

Reagent: cholesterol liquicolor manufactured by human gesellschaft fur biochemical \& diagnostic $\mathrm{mbH}$. Max-planck-Ring 21 .65205 wiesbaden. Germany.

Procedure: $1 \mathrm{ml}$ of cholesterol liquicolor is taken in a test tube waiting up to 5 minutes until it gain the room temperature. Then $10 \mu \mathrm{l}$ of sample is mixed with this reagent and waiting for 5 minutes. The value of the $\mathrm{S}$. cholesterol is then determined by the analyzer which was calibrated before [9] 


\subsection{Triglyceride Determination}

Reagent: TG liquicolor, manufactured by human gesellschaft fur biochemical \& diagnostic $\mathrm{mbH}$. Max-planck-Ring 21 .65205 wiesbaden. Germany.

Procedure: $1 \mathrm{ml}$ of $\mathrm{TG}$ liquicolor is taken in a test tube waiting up to 5 minutes until it gain the room temperature. Then $10 \mu \mathrm{l}$ of sample is mixed with this reagent and waiting for 5 minutes. The value of the TG is then determined by the analyzer which was calibrated before [10]

\subsection{High Density Lipoprotein Determination}

Reagent 1: HDL liquicolor, manufactured by human gesellschaft fur biochemical \& diagnostic mbH. Max-planck-Ring 21.65205 wiesbaden. Germany.

Reagent 2: cholesterol liquicolor, manufactured by human gesellschaft fur biochemical \& diagnostic $\mathrm{mbH}$. Max-planck-Ring 21 .65205 wiesbaden. Germany.

Procedure: $1 \mathrm{ml}$ of HDL liquicolor is taken in a test tube then mix with $500 \mu \mathrm{l}$ of sample. By using centrifugal machine for 10 minutes the mixer is allowed separation. From the separated mixer $10 \mu \mathrm{l}$ is taken and mix with $1 \mathrm{ml}$ cholesterol liquicolor and waiting for 5 minutes. Then value of the HDL is determined by the analyzer which was calibrated before [11].

\subsection{Serum Creatinine Determination}

Reagent 1: Randox Cera (R1a), Rendox laboratories limited, 55 Diamond Road Crumlin

Country Antrin UK BT 29 4QY

Reagent 2: Randox Cera (R1b), Rendox laboratories limited, 55 Diamond Road Crumlin

Country Antrin UK BT 29 4QY.

Procedure: First R1a reagent of $500 \mu 1$ mix with $500 \mu 1$ of $\mathrm{R} 1 \mathrm{~b}$ reagent in a test tube up to 5 minutes until gain the Room temperature. Then $100 \mu 1$ of sample is mixed with this mixed reagent and waiting for 5 minutes. The value of the serum Creatinine is then determined by the analyzer which was calibrated before.

\subsection{Serum Glutamate Pyruvic Acetate (SGPT) Determination}

Reagent 1: BUF

Reagent 1: SUB

Procedure: At first $800 \mu 1$ of BUF is mixed with $200 \mu 1$ of SUB in a test tube and keep it for 5 minutes until gain the Room temperature. Then $100 \mu 1$ of sample is mixed with this mixed reagent and waiting for 5 minutes. The value of the SGPT is then determined by the analyzer which was calibrated before.

\subsection{Statistical Data Analysis}

Results obtained were presented as mean \pm SD. Variation within a set of data was analyzed by

One-way analysis of variance (ANOVA) using the Graph Pad Prism Software (GPPS). Values of $p<0.05$ were taken as statistically significant.

\section{Result and Discussion}

\subsection{Determination of Lipid Profile}

\subsubsection{Determination of the Effects of Total Serum Cholesterol Value}

Result: Effect of administration of $100 \%$ methanolic extract of Borassus flabilifer L. on serum cholesterol of albino rat is shown in Table 2. The result shows that Dose $300 \mathrm{mg} / \mathrm{kg}$ bw and Dose $600 \mathrm{mg} / \mathrm{kg}$ bw of Borassus flabilifer L. caused significant elimination in Total serum cholesterol Table 3 , HDL- cholesterol Table 4, Serum Triglyceride (TG) Table 5, compared with the control. In case of serum Creatinine caused no significant Change in serum Creatinine compared with the control Table 6 and Caused slightly Change in serum glutamate pyruvic acetate (SGPT) compared with the control.

Table 2. Effect of Borassus flabilifer L. on total cholesterol concentration ( $\mathrm{mg} / \mathrm{dl}$ ) value in serum.

\begin{tabular}{llll}
\hline & $\begin{array}{l}\text { Group1, } \\
\text { Control }\end{array}$ & $\begin{array}{l}\text { Group2 (300mg/kg } \\
\text { bw) }\end{array}$ & $\begin{array}{l}\text { Group3(600mg/ } \\
\text { kg bw) }\end{array}$ \\
\hline R1 & 59.0 & 44.7 & 34.6 \\
R2 & 60.5 & 47.6 & 34.3 \\
R3 & 58.7 & 43.9 & 36.4 \\
R4 & 62.7 & 46.7 & 38.7 \\
R5 & 64.2 & 44.5 & 34.1 \\
Mean & 61.02 & 45.48 & 35.62 \\
Mean \pm SD & $61.02 \pm 2.381$ & $45.48 \pm 1.585$ & $35.62 \pm 1.949$ \\
\hline
\end{tabular}

Values are Mean \pm SD of 5 determinations. Values with different alphabetical superscript along a column are significantly different at $\mathrm{P}<0.05$.

Discussion: Results obtained in this study indicate that the extract caused significant elimination in Total serum cholesterol level. The total serum cholesterol lowering effect of Borassus flabilifer L. may be attributed to its ability to increase the excretion of cholesterol. Certain drugs/herbs have been reported to cause enhanced excretion of acidic and neutral steroids. [12] These results suggest that Borassus flabilifer L can be used as antiatherogenic agent for the management of atherosclerosis in man.[13]

Table 3 . Effect of Borassus flabilifer L. on HDL-cholesterol concentration $(\mathrm{mg} / \mathrm{dl})$ value in serum.

\begin{tabular}{llll}
\hline & $\begin{array}{l}\text { Group1, } \\
\text { Control }\end{array}$ & $\begin{array}{l}\text { Group2 (300mg/kg } \\
\text { bw) }\end{array}$ & $\begin{array}{l}\text { Group3(600mg/k } \\
\text { g bw) }\end{array}$ \\
\hline R1 & 43.4 & 55.6 & 58.9 \\
R2 & 47.2 & 58.7 & 60.2 \\
R3 & 43.5 & 53.9 & 57.8 \\
R4 & 45.9 & 57.1 & 63.4 \\
R5 & 43.4 & 53.5 & 64.9 \\
Mean & 44.68 & 55.76 & 61.04 \\
Mean \pm SD & $44.68 \pm 1.768$ & $55.76 \pm 2.181$ & $61.04 \pm 3.01$ \\
\hline
\end{tabular}

Values are Mean \pm SD of 5 determinations. Values with different alphabetical superscript along a column are significantly different at $\mathrm{P}<0.05$

Discussion: Results obtained in this study indicate that the extract caused significant elevation in serum HDL-Cholesterol level. The total serum HDL-Cholesterol rising effect of Borassus flabilifer L. may be attributed to its 
ability to decrease the excretion of serum HDL-cholesterol. HDL-Cholesterol are synthesized in the liver, this result demonstrates the ability of Borassus flabilifer L. to influence liver metabolism towards increased synthesis of lipids. The high levels of serum HDL-cholesterol may be due to a number of factors such as the increased availability of fatty acids for esterification [14] reduced catabolism of LDL, inhibition of tissues lipases, activation of acetyl-CoA carboxylase.

Table 4. Effect of Borassus flabilifer L. on total Triglyceride (TG) concentration $(\mathrm{mg} / \mathrm{dl})$ value in serum.

\begin{tabular}{llll}
\hline & $\begin{array}{l}\text { Group1, } \\
\text { Control }\end{array}$ & $\begin{array}{l}\text { Group2 (300mg/kg } \\
\text { bw) }\end{array}$ & $\begin{array}{l}\text { Group3(600mg/ } \\
\text { kg bw) }\end{array}$ \\
\hline R1 & 42.8 & 45.27 & 46.55 \\
R2 & 45.2 & 48.62 & 48.97 \\
R3 & 45.6 & 42.50 & 49.33 \\
R4 & 43.0 & 41.24 & 48.54 \\
R5 & 42.7 & 45.93 & 46.39 \\
Mean & 43.86 & 44.712 & 47.96 \\
Mean \pm SD & $43.86 \pm 1.417$ & $44.712 \pm 2.916$ & $47.96 \pm 1.386$ \\
\hline
\end{tabular}

Values are Mean \pm SD of 5 determinations. Values with different alphabetical superscript along a column are significantly different at $\mathrm{P}<0.05$.

Discussion: Results obtained in this study indicate that the extract caused significant elevation in serum TG level. The total serum triglyceride rising effect of Borassus flabilifer L. may be attributed to its ability to decrease the excretion of serum TG.

Like HDL-Cholesterol Triglyceride (TG) also synthesized in the liver, this result demonstrate the ability of Borassus flabilifer L. to influence liver metabolism towards increased synthesis of lipids. Acetyl-CoA and glycerol phosphate are the precursor of the production of triglyceride[15] Borassus flabilifer L. may influence the liver for the deposition of Acetyl-CoA and glycerol phosphate in the hepatocyte during glycolysis and acetyl-CoA process that causes the synthesis of TG and increased the level of TG in blood serum.

Table 5. Effect of Borassus flabilifer L. on total S.Creatinine Concentration $(\mathrm{mg} / \mathrm{dl})$ in serum.

\begin{tabular}{|c|c|c|c|}
\hline & $\begin{array}{l}\text { Group1, } \\
\text { Control }\end{array}$ & $\begin{array}{l}\text { Group2 } \\
(300 \mathrm{mg} / \mathrm{kg} \text { bw })\end{array}$ & $\begin{array}{l}\text { Group3 } \\
(600 \mathrm{mg} / \mathrm{kg} \text { bw) }\end{array}$ \\
\hline $\mathrm{R} 1$ & 0.4 & 0.6 & 0.5 \\
\hline R2 & 0.6 & 0.5 & 0.7 \\
\hline $\mathrm{R} 3$ & 0.6 & 0.7 & 0.6 \\
\hline $\mathrm{R} 4$ & 0.3 & 0.5 & 0.8 \\
\hline R5 & 0.7 & 0.6 & 0.6 \\
\hline Mean & 0.52 & 0.58 & 0.64 \\
\hline Mean \pm SD & $0.52 \pm 0.16432$ & $0.58 \pm 0.08367$ & $0.64 \pm 11402$ \\
\hline
\end{tabular}

Values are Mean \pm SD of 5 determinations. Values with different alphabetical superscript along a column are significantly different at $\mathrm{P}<0.05$

Discussion: Serum creatinine is an important indicator of renal health because it is an easily measured by product of muscle metabolism that is excreted unchanged by the kidneys.
Creatinine itself is produced via a biological system involving creatine, phosphocreatine and adenosine triphosphate. Creatinine is synthesized primarily in the liver from the methylation of glycocyamine by S- adenosyl methionine. It is then transported through blood to the other organs, muscle, and brain, where, through phosphorylation, it becomes the high-energy compound phosphocreatine. During the reaction, creatine and phosphocreatine are catalyzed by creatine kinase, and a spontaneous conversion to creatinine may occur. Creatinine is removed from the blood chiefly by the kidneys, primarily by glomerular filtration, but also by proximal tubular secretion. An alternate estimation of renal function can be made when interpreting the blood concentration of creatinine along with that of urea. BUN- to-creatinine ratio can indicate other problems besides those intrinsic to the kidney; for example, a urea level raised out of proportion to the creatinine may indicate a pre renal problem such as volume depletion.

Results obtained in this study indicate that the extract caused no significant change in serum creatinine level. So it can be said that there is no effect of Borassus flabilifer L. on the functioning nephrons of kidney and glomerular filtration rate (GFR).

Table 6. Effect of Borassus flabilifer L. on total Serum glutamate pyruvic acetate (SGPT). Concentration (IU/L) in serum.

\begin{tabular}{|c|c|c|c|}
\hline & Group1, Control & $\begin{array}{l}\text { Group } 2 \\
(300 \mathrm{mg} / \mathrm{kg} \text { bw })\end{array}$ & $\begin{array}{l}\text { Group3 } \\
(600 \mathrm{mg} / \mathrm{kg} \text { bw) }\end{array}$ \\
\hline $\mathrm{R} 1$ & 44.6 & 45.0 & 44.4 \\
\hline $\mathrm{R} 2$ & 45.4 & 42.8 & 47.2 \\
\hline R3 & 40.7 & 41.9 & 45.3 \\
\hline R4 & 42.3 & 47.2 & 42.7 \\
\hline $\mathrm{R} 5$ & 40.5 & 40.6 & 48.1 \\
\hline Mean & 42.7 & 43.5 & 45.54 \\
\hline Mean \pm SD & $42.7 \pm 2.2304$ & $43.5 \pm 2.6172$ & $45.54 \pm 2.16402$ \\
\hline
\end{tabular}

Values are Mean \pm SD of 5 determinations. Values with different alphabetical superscript along a column are significantly different at $\mathrm{P}<0.05$.

Discussion: Results obtained in this study indicate that the extract caused slightly change in serum SGPT (ALT) level. Significantly elevated levels of ALT (SGPT) often suggest the existence of other medical problems such as viral hepatitis, diabetes, congestive heart failure, liver damage, bile duct problems, infectious mononucleosis, or myopathy. For this reason, ALT is commonly used as a way of screening for liver problems. Results obtained in this study indicate that the extract caused slightly change in serum SGPT (ALT) level at high dose. So it can be said that there is no significant effect of Borassus flabilifer L. on the liver dysfunction, hepatitis or liver cirrhosis.

\section{Conclusion}

$100 \%$ Crude extracts of Borassusflabilifer L. were subjected to toxicological investigation to find out its toxicological effects on the body or the different organs of the body. This investigation on animal body shows that it has significant effect on lipid profile of the serum. Both in high 
dose $\&$ low dose it changes the total serum cholesterol value significantly. It also causes the significant elevation of Serum Triglyceride (TG) level \& HDL-Cholesterol level. So the results obtained in this study indicate that $100 \%$ crude extract of Borassusflabilifer L. Possess phytochemicals with positive effects on lipid profile in rats. This validates its traditional uses in the management of cardiovascular diseases arisingfrom dyslipidaemia.

On the other hand $100 \%$ Crude extracts of Borassusflabilifer $L$. does not show any significant change in the Serum Creatinin Value both in low and high dose after a long time administration so this crude extracts have no significant toxic effects on Glomerular Filtration Rate(GFR) and not responsible for any types of Renal dysfunction.

The long time oral administration of this crude extracts causes slightly change of the SGPT(ALT) value at high doses but causes no significant changes at low doses.So it can be said that it has no significant toxic effect on liver Function.

\section{Acknowledgement}

I would like to express my sincere gratitude and deep appreciation to my honorable teacher and supervisor, Dr. Shohel Rana, Professor, Department of Pharmacy, Jahangirnagar University, Savar, Dhaka-1342, for this expert planning, sincere direction, supervision, individual advices, encouragement, and continuous follow up from the very beginning of this work. At the last stage of my dissertation he helped me a lot by checking the proof and suggesting necessary modification/correction that improve the quality of the desertion.

My sincere thanks go to Palash Karmakar(Assistant professor) and my co-supervisor, Department of Pharmacy, Noakhali Science \& Technology University, for his support which helped me a great deal to enrich the dissertation.

It is also a great pleasure for me to offer deepest gratitude to IshtiakAhmed, executive R\&D, Incepta Pharmaceuticals Ltd. for his continuous follow up, counseling, affectionate attitude in carrying out the whole dissertation. Without his help and encouragement throughout the work it would be difficult for me to complete the task.

I would like to acknowledge the helping hand of the authority of MEDIPLUS DIAGNOSTIC CENTER, 25Misson road ChandpurSadar, Chandpur for supporting me to find out important biochemical value of this research by their instruments and reagents.

\section{References}

[1] Ghani A. 2003. Medicinal Plants of Bangladesh: Chemical Constituents and Uses. $2^{\text {nd }}$ Ed. The Asiatic society of Bangladesh, Dhaka, Bangladesh, pp. 7, 74-76, 99, 115, $117-118,161,217,226,276,315,328,365,367,402,428,430$, 433-434, 525-526, 528-530.

[2] Ariyasena D. D., Jansz, E. R., Jayesekera s., Abesekara A. M. 2000. J. Sci. Food Agric., 80:1763-1766.

[3] Halliwell B., Gutteridge J. M.C., 1984. Free Radical in Biology and Medicine. Oxford, Oxford University Press.

[4] Cragg G. M., Newan D. j., 2005. Plants as source of anticancer agents. J Ethnopharmacol., 100: 72-79.

[5] Balunas M.J., Kinghorn A. D., 2005. Drug Discovery from medicinal plants. Life Sci., 78:431-441. Kimura Y., 2005. New anticancer agents: in Vitro and in Vivo evaluation of the antitumor and antimetastatic action of various compounds isolated from medicinal plants. In Vivo.,19: 37-60.

[6] Dulger B., Celikler S., Kirmizi S., 1998. Antimicrobial activity of hyper Perforratum(L). KUKEM Dergisi, 21: 33-40, Ahmed I., Beg A. Z., 2001. Antimicrobial and phytochemical Studies on 45 Indian medicinal plants againist multi-drug resistant human pathogens. J. Enthopharmacpl., 74:113-123, Lopez A., Hudson J. B., Towers G. H. N., 2001. Antimicrobial activities of Colombian medicinal plants. J. Ethnopharmacol., 77: 189-196.

[7] Vermani K., Grag S., 2002. Herbal medicines for sexually transmitted diseases and AIDS. J. Ethanopharmacol., 80: $49-66$.

[8] Cragg G. M., Newman D. J. Sanders K. M., 1997. Natural products in drug discovery and development. J. Nat. Prod.,60: 52-60.

[9] F. Zoppi, D Fellini, Clin. Chem., 1976, 22, 690-691.

[10] Trinder, Ann. Clin. Biochem., 1969, 6, 24-27.

[11] WT Friedwald, RI Levy, DS Fredrickson, Clin. Chem., 1972, $18,499-502$.

[12] FV Udoh, Fitoterapia, 1998, 69 (2), 141-146.

[13] FC Zhan, PJ Casey, Annual Rev. Biochem., 1996, 65, 241-246.

[14] KH Bopanna, J Kannan, S Gadgil, ER Balaraman, SP Rathore, Indian Journal of [Pharmacology, 1997, 29, 162-167.

[15] GL Vega, MF Weiner, AM Lipton, Arch Neurol., 2003, 60, 510-515. 